\title{
Knowledge, Attitude, and Practices Regarding COVID-19 Among Chronic Illness Patients at Outpatient Departments in Ho Chi Minh City, Vietnam
}

This article was published in the following Dove Press journal:

Risk Management and Healthcare Policy

\section{Giao Huynh (D) \\ Minh Quan Nguyen (iD ${ }^{2}$ \\ Thien Thuan Tran (D) \\ Van Tap Nguyen (iD ' \\ Truong Vien Nguyen (D) \\ Thi Hoai Thuong Do' \\ Phi Hong Ngan Nguyen ${ }^{3}$ \\ Thi Hoai Yen Phan' \\ Thanh Thuy Vu (D) ${ }^{3}$ \\ Thi Ngoc Han Nguyen (D) ${ }^{4}$ \\ 'Faculty of Public Health, University of Medicine and Pharmacy at Ho Chi Minh City, Ho Chi Minh City, Vietnam; \\ ${ }^{2}$ Department of Scientific Research, Thu Duc District Hospital, Ho Chi Minh City, Vietnam; ${ }^{3}$ Department of Scientific Research, District 2 Hospital, Ho Chi Minh City, Vietnam; ${ }^{4}$ Infection Control Department, University Medical Center Ho Chi Minh City, Ho Chi Minh City, Vietnam}

Correspondence: Minh Quan Nguyen Thu Duc District Hospital, Ho Chi Minh City, Vietnam

Tel +84989777722

Email minhquanbvtd@gmail.com

Giao Huynh

University of Medicine and Pharmacy at Ho Chi Minh City, 217 Hong Bang Street, District 5, Ho Chi Minh City, Vietnam

Tel +84908608338

Email hgiaoytcc@ump.edu.vn
Background: The novel coronavirus disease (COVID-19) has become a major threat to human life around the world. This study aims to assess the knowledge, attitude, and practices regarding COVID-19 among people with chronic diseases at the outpatient departments in Ho Chi Minh City.

Methods: A cross-sectional study was carried out between February and March 2020 using a convenience sampling strategy in three hospitals in Ho Chi Minh City (HCMC) via the use of a structured self-administered questionnaire. Factors relating to practices, prevalence ratio (PR), and 95\% confidence interval were estimated by using the Poisson regression with robust options. P-value $<0.05$ was considered as statistically different.

Results: A total of 522 participants had a mean age of $51.5 \pm 10.6$ years. Most of them reported seeing information regarding the COVID-19 pandemic (93.7\%) via television and social media $(72.8 \%$ and $62.1 \%$, respectively). Just over two-thirds of the participants (68.4\%) answered with sufficient knowledge of COVID-19. Most respondents had a positive attitude toward COVID-19 (90.8\%), although some misconceptions existed. Almost over three-fourths of them $(77.2 \%)$ maintained good practices for prevention. The rate of good practices in those who had sufficient knowledge was 1.24 times greater than that among those who had insufficient knowledge (PR 1.24, 95\% CI: 1.10-1.41, P<0.05). Also, the rate of good practices in males was lower than that of females (PR: $0.91,95 \% \mathrm{CI}$ : 0.83-0.99, $\mathrm{P}<0.05)$.

Conclusion: There still exists an amount of insufficient knowledge and negative attitude regarding COVID-19, which may be barriers to good prevention practices among chronic illness patients. Education programs need to continue via television and social media and emphasize that people with chronic diseases are more likely to experience severe symptoms, including death from COVID-19. Additionally, management authorities should prolong specific policies to protect the more vulnerable in our community.

Keywords: knowledge, attitude, practice, COVID-19, chronic disease

\section{Background}

The COVID-19 was first reported in Wuhan, China in December 2019, which has been reported as an emerging respiratory infection, with the number deaths exceeding other well-known viruses such as Severe Acute Respiratory Syndrome (SARS) and Middle East Respiratory Syndrome (MERS). The impact of the COVID-19 
pandemic has caused an excessive loss of life and hardship, and become a major threat to human life around the world. ${ }^{1-3}$ In the first half of 2020, the number of cases grew exponentially in many countries with infected cases having been recorded almost everywhere, including hospitals and in the community. ${ }^{4}$ By 21 July 2020, the World Health Organization (WHO) recorded 14,562,550 confirmed cases leading to 607,781 deaths worldwide, with the highest number of confirmed cases and deaths recorded in the Americas and Europe. ${ }^{1}$ Clinical symptoms of infected persons have been reported to include cough, fever, and shortness of breath, with the average incubation period of 5-6 days, but can be up to 14 days. ${ }^{5}$ In terms of transmission, WHO has stated that touching contaminated droplets on surfaces or objects, or close contact with an infected person, within about $1 \mathrm{~m}$ (3 feet), can facilitate transmission between humans. ${ }^{6}$ The challenge with this virus is that many victims have reported mostly mild symptoms. This has contributed to the threat to public health because the detection of infected persons can be very difficult in the early stages. Some sufferers could develop more serious symptoms with a small number resulting in death. Since the first case was reported at the end of January 2020, Vietnam has recorded 396 confirmed cases across the country but most of the cases seemed to be centered around the two big cities of Hanoi and Ho Chi Minh City. ${ }^{7}$ Due to the management of the virus, Vietnam is becoming a noted country having successfully isolated the COVID-19 pandemic via rapid response, clear leadership, and support by clinical care and public health response. $^{8}$ At the beginning of the pandemic, all the suspected cases were isolated for 2 weeks. All were tested and followed, as well as the country having mobilized teams to respond and control the spread of COVID-19 in the community. In particular, people with chronic diseases were advised to stay home and practice social distancing. In some big cities including Ho Chi Minh City, doctors and nurses checked the condition of these patients at their homes and promoted online medical advice for older patients or they were examined and received quality treatment at the hospital once every 2 months instead of once a month. ${ }^{9}$ It is widely noted that people over 60 years old with underlying noncommunicable diseases (NCDs) like diabetes, heart, or lung disease, were more likely to be a high risk of severe disease and death. ${ }^{10}$ Currently, there is no recommended effective treatment with vaccine development still in progress. Thus, it is necessary to perform health education interventions aimed towards preventive measures and how to avoid being exposed to the virus in the community, especially for people with chronic diseases. ${ }^{11}$ Some previous studies about infectious diseases such as SARS, MERS showed knowledge and attitudes were associated with the level of practices to prevent the spread of disease. ${ }^{12,13}$ However, some findings showed a lack of understanding about this pandemic and available processes to prevent transmission. ${ }^{14,15}$ Therefore, assessing the knowledge, attitude and practices toward COVID-19 plays an important role, especially in patients with a chronic illness, which will help to develop the effective educational interventions to ensure safe and quality care while stopping onwards viral transmission.

\section{Methods}

\section{Study Population}

A cross-sectional study was conducted between February and March 2020. A total of 522 people with chronic diseases such as diabetes and hypertension at outpatient departments in three hospitals in HCMC including District 2, Thu Duc, and Binh Thanh were recruited for this study. A convenience sampling strategy was considered on all the people with chronic diseases who have been diagnosed by a physician and more than 18 years old. All participants were informed regarding the objective of the study and completed the consent form before participating.

\section{Data Collection}

\section{Study Instrument}

The questionnaire was designed by using frequently asked questions regarding COVID-19 from the WHO webpage, and Ahmed M. Asaad's questionnaire about the Middle East Respiratory Syndrome Coronavirus (MERS-CoV), and our questionnaire about COVID-19 among healthcare workers. ${ }^{16-18}$ Firstly, a pilot study was done to test 10 subjects at the outpatient department at District 2 Hospital to assess comprehension and accessibility of the questionnaire, with no necessary reformation recognized from participants. The final structured questionnaire was defined by the authors. Data were collected via the use of a structured self-administered questionnaire, which included four main domains. The first section elicited information on demographic characteristics including age, gender, occupation, education, and the source information of COVID-19 knowledge including types of face masks. The second section was designed to assess participants' knowledge of COVID-19 including a set of 9 yes/ 
no options. The third section estimated the attitude toward COVID-19, to which participants were asked to respond using a 5-point Likert scale ranging from strongly agree to strongly disagree. The final section recorded the participants' practices using a set of three open-ended questions. All were arranged at the hospital of District 2, Thu Duc, and Binh Thanh.

\section{Method of Analysis}

To assess the knowledge score, nine items of knowledge on the questionnaire were measured, each correct answer was counted as 1 point with no points allotted for an incorrect answer. The general knowledge score was recorded from 0 (no correct answers) to 9 (all correct answers), and the cut-off level of $\geq 6$ was set as the level of sufficient knowledge. ${ }^{19}$ To assess 6 items of attitude, the scores were based on 5 point Likert scales, ranged from strongly agree to strongly disagree. For each attitude item, the point was assigned into 1 point (strongly agree and agree) and 0 points (strongly disagree, disagree, undecided), the cut-off level of total attitude items $\geq 4$ indicated as a positive general attitude. Response questions for 3 items of the practices ranged from 0 (no correct answers) to 3 points (all correct answers), a total of $\geq 2$ points for good practices. The data were calculated using Stata 13 and Epidata 3.1 software. Factors with practices, prevalence ratio (PR), and 95\% confidence interval (95\% CI) were estimated by Poisson regression with robust options. All factors which had a significance level P-value $<0.20$ in the bivariate analysis were included in the multivariate analysis by the Poisson regression model. P-value $<0.05$ was considered as statistically different.

\section{Ethical Approval}

Our research complied with the Declaration of Helsinki. All the eligible participants were informed about the aims of the study, they signed a consent form before participation. The protocols of the study were approved by the Ethics Council of University of Medicine and Pharmacy at Ho Chi Minh City (protocol number 162/UMP - BOARD).

\section{Results}

As shown in Table 1, a total of $522(87.0 \%)$ participants completed and returned the questionnaire from the outpatient department of the three hospitals. Some of the main characteristics of participants were mainly in the mean age of $51.5 \pm 10.6$ years, with $55.7 \%$ being female, $(31.1 \%)$ public workers and (61.9\%) having completed high school level. Most of them reported seeing information regarding the COVID-19 outbreak globally (93.7\%), as having their main source as television and social media $(72.8 \%$ and $62.1 \%$, respectively), while only $34.3 \%$ of participants gathered information from the websites of the Hospitals or Health Ministry. The majority (98.3\%) reported using a face mask. Table 2 provides an overview of knowledge and attitude regarding COVID-19. The majority of participants knew COVID-19 can be spread via respiratory droplets from infected people $(92.5 \%)$, and potentially causing death (91.8\%). Almost over three quarters of participants reported being aware that COVID-19 is a type of virus $(79.7 \%)$ and also having knowledge of symptoms including fever, cough, sore throats, and shortness of breath (62.1\%). Additionally, they reported knowledge of the vaccine not being available (69.5\%). Further, it was recorded that the knowledge that individuals should be washing hands with soap and water and wearing face masks to prevent the infection was $60.9 \%$. Besides, $63.2 \%$ of respondents knew that patients with underlying chronic diseases are at a higher risk of severe disease and death. Additionally, less than half of the respondents indicated they were aware of the isolation period being 2 weeks if a person is suspected of carrying the virus (43.5\%). The overall result of the items of sufficient knowledge was reported as $68.4 \%$. For assessing attitude, $90.8 \%$ of respondents had a positive attitude regarding COVID-19, the majority of participants agreed with the statement that they will accept isolation if they contracted the virus (95.0\%), people with COVID-19 should be kept in isolation in health facilities $(95.8 \%)$, and transmission can be prevented by washing hands with soap frequently $(91.8 \%)$, as well as the willingness to receive the vaccination if a vaccine was available (91.8\%). However, only a little over half of those surveyed believed that their family members and individuals may be at risk of COVID-19 infection (64.8\% and $66.5 \%$, respectively). In response to practices toward COVID-19 prevention, it can be seen from the data in Table 3 that $77.2 \%$ of participants reported having good practices. However, only $40.4 \%$ of respondents knew that the average time for washing hands was at least $20 \mathrm{~s}$. As Table 4 showed, there was a significant correlation between knowledge, gender, and practices, whereby the rate of good practices in those who had sufficient knowledge was 1.24 times greater than that among those who had insufficient knowledge (PR 1.24, 95\% CI: $1.10-1.41, \mathrm{P}<0.05)$. Also, the study showed that the rate of good practices in males was lower than that of females (PR: 0.91, 95\% CI: 0.83-0.99, p<0.05). 
Table I Baseline Characteristics of Patients $(n=522)$

\begin{tabular}{|c|c|}
\hline Characteristics & $\begin{array}{l}\text { Participants } \\
\text { No.(\%) }\end{array}$ \\
\hline $\begin{array}{l}\text { Mean Age } \pm \text { SD (Min-Max) } \\
\quad<50 \text { year-old } \\
\geq 50 \text { year-old }\end{array}$ & $\begin{array}{l}51.5 \pm 10.6(26-87) \\
224(42.9) \\
298(57.1)\end{array}$ \\
\hline Gender (female) & 290 \\
\hline $\begin{array}{l}\text { Academic level } \\
<\text { Primary school } \\
\text { Secondary school } \\
\text { > High school }\end{array}$ & $\begin{array}{l}80(15.3) \\
119(2.8) \\
323(61.9)\end{array}$ \\
\hline $\begin{array}{l}\text { Occupation }(n=521) \\
\text { Worker } \\
\text { Housewife } \\
\text { Officer } \\
\text { Business, trading } \\
\text { Retired }\end{array}$ & $\begin{array}{l}162(31.1) \\
126(24.2) \\
126(24.2) \\
57(10.9) \\
50(9.6)\end{array}$ \\
\hline $\begin{array}{l}\text { The outbreak of COVID-19 is } \\
\text { happening globally in } 2020 \text { (yes) }\end{array}$ & 489 (93.7) \\
\hline $\begin{array}{l}\text { Source of information (yes) } \\
\text { Television } \\
\text { Social media } \\
\text { Websites of hospital/Health Ministry } \\
\text { Friends, relatives } \\
\text { Unheard }\end{array}$ & $\begin{array}{l}380(72.8) \\
324(62.1) \\
179(34.3) \\
158(30.3) \\
10(1.9)\end{array}$ \\
\hline Use mask (yes) & $513(98.3)$ \\
\hline $\begin{array}{l}\text { Type of mask } \\
\text { Medical masks } \\
\text { Cloth mask } \\
\text { N95 mask }\end{array}$ & $\begin{array}{l}418(80.1) \\
143(27.4) \\
19(3.6)\end{array}$ \\
\hline
\end{tabular}

\section{Discussion}

\section{Characteristics of Participants}

This is the first study of its type to assess the knowledge, attitudes, and practices of people with chronic diseases in Vietnam, and it was performed at the first stage of the pandemic. In the beginning, Vietnam applied a multitude of strict measures to prevent COVID-19, this included installing strict social distancing in the first half of April 2020. ${ }^{8}$ As of July 2020, the spread of COVID-19 is continuing to rapidly increase in many countries around the world and Vietnam cases are continuing to grow with the support of the healthcare environments in Vietnam. ${ }^{1,8}$ Therefore, there is an immediate need for effective prevention through enhancing knowledge, attitude, and practices by high-risk persons in the community. ${ }^{8}$ The characteristics of participants in our study were mainly female $(55.7 \%)$ and educated $(61.9 \%)$ to high
Table 2 Knowledge and Attitude of Patients Toward COVID-19 $(n=522)$

\begin{tabular}{|c|c|}
\hline Item (Correct Answer) & $\begin{array}{l}\text { Correct } \\
\text { Answer } \\
\text { No.(\%) }\end{array}$ \\
\hline \multicolumn{2}{|l|}{ Knowledge toward COVID-19 } \\
\hline COVID-19 is a virus infection (yes) & $416(79.7)$ \\
\hline $\begin{array}{l}\text { COVID-19 spreads via respiratory droplets from } \\
\text { infected people (yes) }\end{array}$ & $483(92.5)$ \\
\hline $\begin{array}{l}\text { Fever, cough, sore throats and shortness breath are } \\
\text { possible symptoms (yes) }\end{array}$ & $324(62.1)$ \\
\hline $\begin{array}{l}\text { The isolation period is two weeks if suspected } \\
\text { infection (yes) }\end{array}$ & $227(43.5)$ \\
\hline COVID-19 vaccine is available in markets (no) & $363(69.5)$ \\
\hline Antibiotics are the first-line treatment (no) & $230(44.1)$ \\
\hline $\begin{array}{l}\text { Washing hands and wearing face masks can prevent } \\
\text { the transmission (yes) }\end{array}$ & $318(60.9)$ \\
\hline $\begin{array}{l}\text { Patients with underlying chronic diseases are more } \\
\text { likely to be severe cases and death (yes) }\end{array}$ & $330(63.2)$ \\
\hline COVID-19 could be fatal (yes) & $479(91.8)$ \\
\hline Sufficient Knowledge (yes) & $357(68.4)$ \\
\hline Attitude toward COVID-19 & \\
\hline You think you will probably get illness (agree) & $347(66.5)$ \\
\hline $\begin{array}{l}\text { You are worried one of your family members may get } \\
\text { an infection (agree) }\end{array}$ & $338(64.8)$ \\
\hline $\begin{array}{l}\text { If getting COVID-19, you will accept isolation in health } \\
\text { facilities (agree) }\end{array}$ & $496(95.0)$ \\
\hline $\begin{array}{l}\text { Transmission of COVID-19 can be prevented by } \\
\text { washing hands frequently (agree) }\end{array}$ & $479(91.8)$ \\
\hline $\begin{array}{l}\text { If a COVID-19 vaccine was available, I would have it } \\
\text { (agree) }\end{array}$ & $479(91.8)$ \\
\hline $\begin{array}{l}\text { COVID- } 19 \text { patients should be kept in isolation in } \\
\text { health facilities (agree) }\end{array}$ & $500(95.8)$ \\
\hline Positive Attitude & $474(90.8)$ \\
\hline
\end{tabular}

Table 3 Practice of Patients Toward COVID-19 Prevention $(n=522)$

\begin{tabular}{|l|l|}
\hline Item (Correct Answer) & $\begin{array}{l}\text { Response } \\
\text { No. (\%) }\end{array}$ \\
\hline $\begin{array}{l}\text { The average time for washing hands } \geq 20 \text { seconds (yes) } \\
\text { Using soap and water to wash your hand continuously }\end{array}$ & $211(40.4)$ \\
(yes) & \\
Wearing face masks in public places (yes) & $435(83.3)$ \\
Good Practice & $403(77.2)$ \\
\hline
\end{tabular}

school level. We found most of the participants reported seeing information regarding the COVID-19 being a Global Outbreak (93.7\%) with the main sources being television and social media ( $72.8 \%$ and $62.1 \%$ ) while only $34.3 \%$ of information was attained via Hospital Websites or the Health Ministry. These results were also described in our previous 
Table 4 Factors Associated with Practice of Patients Toward COVID-19 (n=522)

\begin{tabular}{|c|c|c|c|c|c|c|}
\hline \multirow[t]{2}{*}{ Characteristics } & \multicolumn{2}{|l|}{ Practice } & \multirow{2}{*}{$\begin{array}{l}\text { Unadjusted } \\
\text { p }^{*}\end{array}$} & \multirow{2}{*}{$\begin{array}{l}\text { Unadjusted } \\
\text { PR }(95 \% \mathrm{CI})\end{array}$} & \multirow{2}{*}{$\begin{array}{l}\text { Adjusted } \\
\mathbf{p}^{*}\end{array}$} & \multirow{2}{*}{$\begin{array}{l}\text { Adjusted } \\
\text { PR }(95 \% \mathrm{Cl})\end{array}$} \\
\hline & $\begin{array}{l}\text { Sufficient } \\
\text { No. (\%) }\end{array}$ & $\begin{array}{l}\text { Insufficient } \\
\text { No. (\%) }\end{array}$ & & & & \\
\hline \multicolumn{7}{|l|}{ Knowledge } \\
\hline Sufficient & $297(83.2)$ & $60(16.8)$ & 0.001 & $1.29(1.14-1.46)$ & 0.001 & $1.24(1.10-1.41)$ \\
\hline Insufficient & $106(64.2)$ & $59(35.8)$ & & & & \\
\hline \multicolumn{7}{|l|}{ Attitude } \\
\hline Positive & $37 \mid(78.3)$ & $103(21.7)$ & 0.126 & $1.17(0.96-1.44)$ & 0.272 & $1.12(0.92-1.37)$ \\
\hline Negative & $32(66.7)$ & $16(33.3)$ & & & & \\
\hline \multicolumn{7}{|l|}{ Age } \\
\hline$<50$ & I8I (80.8) & $43(19.2)$ & 0.084 & $1.08(0.99-1.19)$ & 0.402 & $1.04(0.95-1.14)$ \\
\hline$\geq 50$ & $222(74.5)$ & $76(25.5)$ & & & & \\
\hline \multicolumn{7}{|l|}{ Gender } \\
\hline Male & $170(73.6)$ & $61(26.4)$ & 0.089 & $0.92(0.83-1.01)$ & 0.046 & $0.91(0.83-0.99)$ \\
\hline Female & $232(80.0)$ & $58(20.0)$ & & & & \\
\hline \multicolumn{7}{|l|}{ Education level } \\
\hline$<$ Primary school & $53(66.3)$ & 27 (33.7) & & I & & I \\
\hline Secondary school & 87 (73.1) & 32 (26.9) & 0.005 & $1.11(1.03-1.19)$ & 0.103 & $1.06(0.99-1.14)$ \\
\hline$\geq$ High school & $263(8 I .4)$ & $60(18.6)$ & 0.005 & $1.23(1.06-1.43)$ & 0.103 & $1.13(0.98-1.30)$ \\
\hline \multicolumn{7}{|l|}{ Occupation } \\
\hline Worker & 127 (78.4) & $35(21.6)$ & & I & & \\
\hline Housewife & $95(75.4)$ & 31 (24.6) & 0.552 & $0.96(0.85-1.09)$ & - & - \\
\hline Officer & $102(81.0)$ & $24(19.0)$ & 0.591 & $1.03(0.92-1.16)$ & - & - \\
\hline Business, trading & $44(77.2)$ & $13(22.8)$ & 0.852 & $0.98(0.84-1.16)$ & - & - \\
\hline Retired & $35(70.0)$ & I5 (30.0) & 0.264 & $0.89(0.73-1.09)$ & - & - \\
\hline
\end{tabular}

Note: $*$ Z-test for coefficients of Poisson regression model.

study among healthcare workers at District 2 hospital and Khan's study. ${ }^{18,19}$ Thus, it can be suggested that the patients are more interested in television and social media to update their knowledge about COVID-19 than other media forms. Therefore, these findings could help the authorities in Vietnam to develop more options to inform the community with the latest information and prevention measures relating to this pandemic, as well as encourage people to visit the official websites, such as those of the hospitals or the health ministry, to look for reliable health-related information, particularly to educate the minority of respondents who did not know about COVID-19 (1.9\%).

\section{Knowledge and Attitude of Chronic Disease Patients Regarding COVID-19}

The results showed participants had a comprehensive and sufficient knowledge of COVID-19 at $68.4 \%$. The finding in relation to those with a moderate knowledge of the virus was unexpected. This result was similar to Bener A.'s study about SARS but different from Bao-Liang Z's study of COVID-19 in China (70.2\% and $98.6 \%$, respectively). ${ }^{12,20}$ Because our survey was performed in the early period of the pandemic in Ho Chi Minh City, numbers of reported cases were still very low in the local community. This meant that educational programs were not highly developed, to offer information on the dangers of the COVID-19. However, China had been much further into the pandemic, having stated in 2019, so the rate of sufficient knowledge was higher in our findings compared to studies of other viruses. Our study found that only $62.1 \%$ and $60.9 \%$ of respondents knew the signs and symptoms as well as the prevention measures through washing hands and wearing a face mask while $44.1 \%$ of participants had good knowledge of the required treatment for the virus. Therefore, as highlighted by the CDC, the provision of information to the community about the virus, 
its transmission modes, and necessary protective measures played a vital role in controlling the pandemic. ${ }^{11}$ Additionally, there were only $43.5 \%$ and $63.2 \%$ of respondents that were aware of the isolation period and the high risk of severe infection among people with underlying chronic diseases. People with chronic diseases in Vietnam are often examined and received quality treatment once a month at the hospital. These patients may be at risk of contracting the virus in health-care environments, with their lack of knowledge on the risk of infection and severe symptoms. Therefore, the government needs to reconsider isolating at-risk patients at home, which seems a much safer process, rather than exposing them, on a daily basis, to the hospital environment, as well as maintaining social distancing by people with chronic diseases as per WHO's recommendation. ${ }^{7,18}$ According to the findings, there are the changes of policy for patients with chronic diseases, such as having medical consultations at home by doctors and nurses, encouraging them to obtain online medical advice, and changes to hospital policy which permits them to receive medication once every 2 months instead of once a month. ${ }^{9}$ Additionally, community knowledge was improved by increasing the frequency of media messages via social media and television every day to encourage people to perform preventive measures. These have successfully contributed to the control of COVID-19 transmission in the community in Vietnam with no confirmed cases in the community for the past 99 days as of July 23, 2020. ${ }^{7}$ Surprisingly, the vast majority of participants had a positive attitude. These results corroborated the findings of Bao-Liang Z.'s study, ${ }^{20}$ nevertheless, there were still $66.5 \%$ and $64.8 \%$ of participants worried about the likelihood of getting the virus or having a family member contract the virus. These findings were also similar to our study among healthcare workers toward COVID-19. ${ }^{18}$ These results may be explained by the lack of knowledge about the spread of the disease so they did not believe their family and close associates could get the disease, this was dangerous if they contracted COVID-19 and became a source of transmission in the community.

\section{Practices of Chronic Disease Patients Regarding COVID-19 and Associated Factors}

We found that only $40.4 \%$ of participants had good practices relating to the average time for washing hands. This also accords with Akalu et al (2020), which showed a low level of knowledge and practice with only $33.9 \%$ and $47.3 \%$, respectively. ${ }^{15}$ The finding was likely to be related to a lack of knowledge and awareness about the importance of prevention. It was observed that knowledge was significantly associated with the practice, with participants having a good knowledge showing a higher probability of good practices.

Another important finding was that females had better practices than males. It seems possible that these results are due to some researches showed that males are more severely affected and have higher mortality rate from COVID-19. ${ }^{21,22}$ Therefore, educational interventions should continue and make a priority to focus on those at a greater risk, to reduce exposure in the community. Another interesting finding was the vast majority of participants wearing face masks accounted for $98.3 \%$. The majority of them wore face masks in public places $(83.3 \%)$. These findings showed that participants had a positive behavior toward prevention and this is one of the important measures that may prevent the spread of COVID-19 as CDC and WHO's recommendations. ${ }^{23,24}$

\section{Limitation}

Some limitations of our study in interpreting the results because no previous studies have been performed to assess prevention practices toward COVID-19; In this time, we just may collect the study samples at three hospitals in HCMC and the convenience sampling strategy. These may limit the generalization of the results with respect to the outpatient population at all the hospitals of HCMC.

\section{Conclusions}

Insufficient knowledge and negative attitudes regarding COVID-19 were still found in some participants in the community, which may be barriers to good prevention practices. Additional education programs need to continue via television and social media and must emphasize that people with chronic diseases are more likely to be a high risk of developing severe symptoms and death. Besides, management authorities need to maintain current policies to protect them from COVID-19 infection in the community and at healthcare facilities.

\section{Data Sharing Statement}

Available upon request to the first author. 


\section{Acknowledgments}

We wish to acknowledge the cooperation and support of outpatients at the hospital of District 2, Thu Duc, and Binh Thanh for the time and effort that they devoted to the study.

\section{Author Contributions}

All authors made substantial contributions to conception and design, acquisition of data, analysis and interpretation of data, took part in revising the article critically for important intellectual content, gave final approval of the version to be published, and agree to be accountable for all aspects of the work.

\section{Funding}

There is no funding to report.

\section{Disclosure}

The authors declare that they have no competing interests for this work.

\section{References}

1. WHO. Coronavirus disease (COVID-19) pandemic. 2020. Available from: https://www.who.int/emergencies/diseases/novel-coronavirus -2019. Accessed July 21, 2020.

2. WHO. Summary of probable SARS cases with onset of illness from 1 November 2002 to 31 July 2003. 2003. Available from: https://www. who.int/csr/sars/country/table2004_04_21/en/. Accessed July 21, 2020.

3. WHO. WHO MERS global summary and assessment of risk. 2019. Available from: https://apps.who.int/iris/bitstream/handle/10665/ 326126/WHO-MERS-RA-19.1-eng.pdf?ua=1. Accessed July 21, 2020.

4. Sun P, Qie S, Liu Z, et al. Clinical characteristics of hospitalized patients with SARS-CoV-2 infection: a single arm meta-analysis. $J$ Med Virol. 2020;92:612-617.

5. WHO. Clinical management of COVID-19. World Health Organization; 2020.

6. WHO. Getting your workplace ready for COVID-19. 2020. Available from: https://www.who.int/docs/default-source/coronaviruse/gettingworkplace-ready-for-covid-19.pdf?sfvrsn=359a81e7_6. accessed July 21, 2020.

7. Ministry of Health in Vietnam. Situation report COVID-19. 2020. Available from: https://ncov.moh.gov.vn/. Accessed July 21, 2020.

8. Ha BTT, Ngoc Q, Mirzoev T, Tai NT, Thai PQ, Dinh PC. Combating the COVID-19 epidemic: experiences from Vietnam. Int J Environ Res Public Health. 2020;17(9):3125. doi:10.3390/ijerph17093125

9. Tung LT. Social responses for older people in COVID-19 pandemic: experience from Vietnam. J Gerontol Soc Work. 2020;1-6. doi: $10.1080 / 01634372.2020 .1773596$
10. WHO. COVID-19 and NCDs. 2020. Available from: https://www. who.int/internal-publications-detail/covid-19-and-ncds. Accessed July 21, 2020.

11. CDC. How to Protect Yourself. 2020. Available from: https://www. cdc.gov/coronavirus/2019-ncov/prepare/prevention.html. Accessed July 21, 2020.

12. Bener A, Al-Khal A. Knowledge, attitude and practice towards SARS. J R Soc Promot Health. 2004;124(4):167-170. doi:10.1177/ 146642400412400408

13. Albarrak AI, Mohammed R, Al Elayan A, et al. Middle east respiratory syndrome (MERS): comparing the knowledge, attitude and practices of different health care workers. $J$ Infect Public Health. 2019. doi:10.1016/j.jiph.2019.06.029

14. Azlan AA, Hamzah MR, Sern TJ, Ayub SH, Mohamad E. Public knowledge, attitudes and practices towards COVID-19: a cross-sectional study in Malaysia. PLoS One. 2020;15(5):e0233668. doi:10.1371/journal.pone. 0233668

15. Akalu Y, Ayelign B, Molla MD. Knowledge, attitude and practice towards COVID-19 among chronic disease patients at Addis Zemen Hospital, Northwest Ethiopia. Infect Drug Resist. 2020;13:1949-1960. doi:10.2147/IDR.S258736

16. WHO. Q\&A on coronaviruses (COVID-19). 2020. Available from: https://www.who.int/news-room/q-a-detail/q-a-coronaviruses. Accessed July 21, 2020.

17. Asaad AM, El-Sokkary RH, Alzamanan MA, El-Shafei M. Knowledge and attitudes towards Middle East respiratory syndrome-coronavirus (MERS-CoV) among health care workers in south-western Saudi Arabia. East Mediterr Health J. 2019;25.

18. Huynh G, Nguyen TNH, Tran VK, et al. Knowledge and attitude toward COVID-19 among healthcare workers at District 2 Hospital, Ho Chi Minh City. Asian Pac J Trop Med. 2020;13:260.

19. Khan MU, Shah S, Ahmad A, Fatokun O. Knowledge and attitude of healthcare workers about Middle East Respiratory Syndrome in multispecialty hospitals of Qassim, Saudi Arabia. BMC Public Health. 2014;14:1281. doi:10.1186/1471-2458-14-1281

20. Zhong B-L, Luo W, Li H-M, et al. Knowledge, attitudes, and practices towards COVID-19 among Chinese residents during the rapid rise period of the COVID-19 outbreak: a quick online cross-sectional survey. Int $J$ Biol Sci. 2020;16(10):1745-1752. doi:10.7150/ ijbs. 45221

21. Jin JM, Bai P, He W, et al. Gender differences in patients with COVID-19: focus on severity and mortality. Front Public Health. 2020;8:152. doi:10.3389/fpubh.2020.00152

22. Falahi S, Kenarkoohi A. Sex and gender differences in the outcome of patients with COVID-19. J Med Virol. 2020. doi:10.1002/ jmv. 26243

23. CDC. Interim infection prevention and control recommendations for patients with suspected or confirmed coronavirus disease 2019 (COVID-19) in healthcare settings. 2020. Available from: https:// www.cdc.gov/coronavirus/2019-ncov/infection-control/controlrecommendations.html?CDC_AA_refVal=https $\% 3 \mathrm{~A} \% 2 \mathrm{~F} \% 2 \mathrm{Fwww}$. cdc.gov\%2Fcoronavirus\%2F2019-ncov\%2Fhcp\%2Finfectioncontrol.html. Accessed July 21, 2020.

24. WHO. Coronavirus disease (COVID-19) advice for the public: when and how to use masks. 2020. Available from: https://www.who.int/ emergencies/diseases/novel-coronavirus-2019/advice-for-public /when-and-how-to-use-masks. Accessed July 21, 2020. 


\section{Publish your work in this journal}

Risk Management and Healthcare Policy is an international, peerreviewed, open access journal focusing on all aspects of public health, policy, and preventative measures to promote good health and improve morbidity and mortality in the population. The journal welcomes submitted papers covering original research, basic science, clinical \& epidemiological studies, reviews and evaluations, guidelines, expert opinion and commentary, case reports and extended reports. The manuscript management system is completely online and includes a very quick and fair peer-review system, which is all easy to use. Visit http://www.dovepress.com/testimonials.php to read real quotes from published authors. 